\title{
Cs FEED TESTS AND EMITTANCE MEASUREMENTS ON A MODIFIED MC-SNICS ION SOURCE FOR RADIOCARBON AMS
}

\author{
John Southon ${ }^{1,2} \cdot$ Guaciara dos $\operatorname{Santos}^{1} \bullet$ Baoxi Han ${ }^{3}$
}

\begin{abstract}
We report on 2 recent developments in an ongoing program of characterizing and improving the National Electrostatics Corp. (NEC) MC-SNICS ion source at University of California (UC) Irvine's Keck AMS laboratory. First, we have investigated the possibility of modifying a large-body (134-sample) MC-SNICS to incorporate the UC Irvine Cs oven and vacuum-insulated Cs feed tube, which provide better confinement of Cs than the standard NEC setup. In our 40-sample source, the feed tube enters the source housing directly below the ionizer assembly. This area cannot be accessed for machining on the 134-sample source, but we have successfully tested a modified geometry where the delivery tube enters the body via the source end flange. Second, we recently installed a second beam profile monitor in the injection line of our spectrometer to allow us to make online emittance measurements. At full output $\left(150 \mu \mathrm{A}\right.$ of $\mathrm{C}^{-}$at $\left.55 \mathrm{keV}\right)$, the emittance of our source at $8 \mathrm{kV}$ sputtering voltage is approximately $40 \pi \mathrm{mm} \mathrm{mrad}$.
\end{abstract}

\section{INTRODUCTION}

University of California (UC) Irvine's Keck AMS facility has operated a 40-sample NEC MCSNICS source (Norton 1992) since mid-2002, and development of the source to increase output and improve reliability and serviceability has been ongoing. Major modifications are described in detail in Southon and Santos $(2004,2006)$. They include: a sliding service platform for mounting the source for easy maintenance; better control of Cs via a redesigned Cs oven and feed line plus cooling on the downstream flange of the source body; a new extractor/Einzel lens assembly plus replacement of NEC's pre-acceleration tube with a larger diameter insulator for better pumping; the use of spherical ionizer assemblies for better focusing of Cs and higher sample use efficiency; and replacing NEC's Cs focus electrode with an immersion lens at cathode potential for better negative ion focusing.

The modified source routinely produces $\mathrm{C}^{-}$currents of $150 \mu \mathrm{A}$ from 1-mg graphite samples, and is reliable and easy to service. Full performance details are given in Southon and Santos (2006). We stress that all of the changes outlined above, including several that require machining of the source housing itself, have been retrofitted to an existing 40-sample source and could be duplicated in any AMS lab with access to good machining and welding capabilities.

Here, we report briefly on 2 recent developments: the testing of a new Cs feed geometry, which potentially allows some of these modifications to be applied to the larger 134-sample version of MC-SNICS; and a measurement of the source emittance.

\section{EXPERIMENTAL Cs FEED}

A major factor in the success of the modified source has been the incorporation of a new Cs oven and vacuum-insulated Cs feed line (Figure 1), based on a Lawrence Livermore/CAMS design (Southon and Roberts 2000). The double-walled feed line enters the source body via a cooled pressure-plate O-ring vacuum seal. Releasing 2 clamp bolts on the pressure plate allows the oven and feed line assembly to be screwed by hand on to a hollow stud in the ionizer assembly. This stud connects to a circular gallery containing 6 apertures through which Cs jets out directly onto the ionizing surface. The Cs feed tube is heated by conduction from the ionizer assembly, and blockages of the line have

\footnotetext{
${ }^{1}$ Department of Earth System Science, University of California, Irvine, California 92697-3100, USA.

${ }^{2}$ Corresponding author: Email: jsouthon@uci.edu.

${ }^{3}$ Department of Geology and Geophysics, Woods Hole Oceanographic Institution, Woods Hole, Massachusetts 02543, USA.
} 
been completely eliminated. In addition, this arrangement provides far better confinement of Cs than the standard NEC setup, and this has led to a 50\% reduction in Cs consumption and to a marked decrease in arcing in both the source itself and the downstream extractor/Einzel lens assembly.

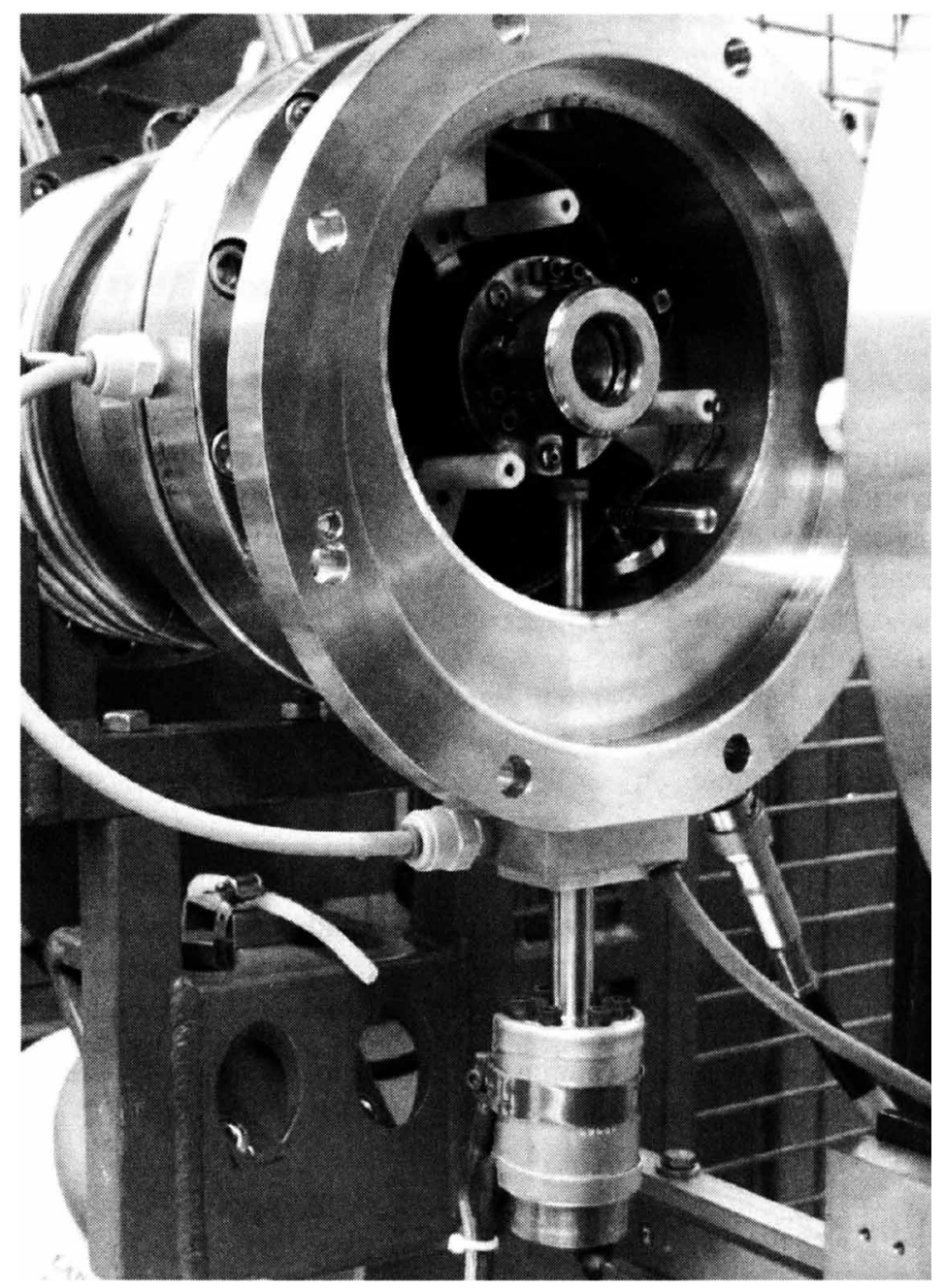

Figure 1 The UC Irvine 40-sample MC-SNICS ion source, viewed from the upstream (sample changer) end. The Cs oven and feed tube below the source, and the connection to the spherical ionizer assembly, are shown. The cathode immersion lens has been removed from the 3 insulating posts to show the ionizer assembly. The spring-loaded plunger to the lower right of the ionizer assembly supplies cathode voltage to the sample wheel.

In our 40-sample MC-SNICS, the Cs feed mounts directly under the ionizer assembly (Figure 1), but on the larger 134-sample version of the source, stiffening ribs cut off all access to this region of the housing (Figure 2). We have recently tested a modified geometry on the 40 -sample source where the cooled block and pressure-plate O-ring seal for the Cs feed are shifted downstream and mounted on a port in the downstream flange, not the source housing. A tube extending downstream from the ionizer assembly terminates in the hollow stud that mates with the Cs feed tube. This configuration pro- 
duced $\mathrm{C}^{-}$currents of 120-150 $\mu \mathrm{A}$ and showed no evidence of Cs clogging. Thus, in spite of the increased overall length of the feed line, heating by conduction from the ionizer assembly was sufficient to keep the line open.

The significance of these results is that in principle this geometry could be applied to the large-body source. To implement the new Cs feed, the ionizer heater feedthrough shown in Figure 2 would be converted into a Cs feed by milling off the VCR fitting. A cooled block with 2 pressure plate O-ring seals would be used: an upper O-ring would seal the block to the remaining stub of the feedthrough and a lower O-ring would accommodate the outer tube of the vacuum-insulated Cs line. The oven would sit below the lower transverse rib in Figure 2. Power for the ionizer heater would enter the source via the old Cs focus feedthrough at the top of the source housing (not shown). This is available because the immersion lens that replaces the Cs focus electrode in the modified source is at cathode potential and does not require a separate feedthrough.

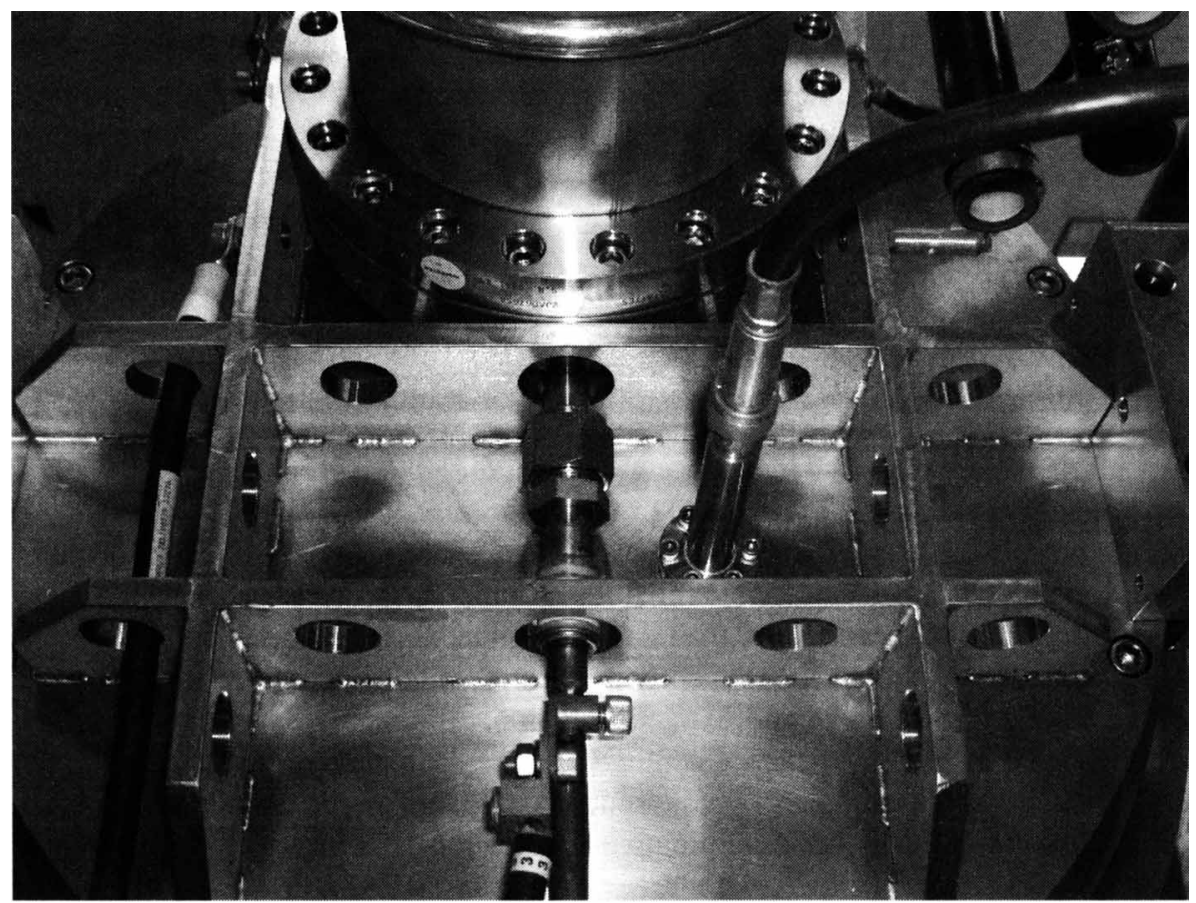

Figure 2 The 134-sample MC-SNICS, seen from downstream and below. The ionizer heater feedthrough can be seen extending down from the bottom of the downstream source flange, and the cathode feedthrough is at center right. The large diameter of the sample wheel and its enclosing chamber requires the use of stiffening ribs, which block all access to the source housing below the ionizer assembly.

\section{EMITTANCE MEASUREMENTS}

It is widely understood that high-precision AMS measurements are difficult, if not impossible, if severe beam losses on apertures or other components of the beam transport system are present. An obvious inference is that many problems in AMS spectrometers may ultimately be traced to overoptimistic assumptions about ion source emittances. Von Reden et al. (2005) recently measured beam divergences from a spherical ionizer MC-SNICS, but those measurements were performed at $\mathrm{C}^{-}$currents of about 30 to $70 \mu \mathrm{A}$ (K von Reden, personal communication). We see large changes in 
beam profiles from our MC-SNICS as the source warms up and approaches full output, and other high-intensity sources (Southon and Roberts 2000) show similar behavior. Calculations show that this effect is probably due to the increasing influence of space charge effects as Cs and negative ion currents increase (von Reden et al. 1998; Weisser et al. 2002). Emittance measurements at full intensity are therefore important for properly characterizing the source output.

We recently installed an additional beam profile monitor (BPM) in the source pump tee in the injection line of our AMS system, to allow us to make online emittance measurements. The new BPM supplements an existing one further downstream, close to the beam waist at the entrance gap lens for the injection bouncer (Southon et al. 2004). The tee also contains steerers and a Faraday cup, so space was limited and there was no room for the usual cylindrical secondary electron collector around the rotating helical BPM wire. The wire was therefore electrically isolated and the beam profile signal was taken directly from it. No changes to the BPM readout system were required, and the signal is completely normal apart from the reversed polarity.

The presence of 2 BPMs provides the capability to measure beam emittances. If $r_{1}$ and $r_{2}$ are the beam radii at 2 BPMs separated by a distance $L$, and the beam is focused to a waist at BPM \#2, then:

$$
r_{1}^{2}=r_{2}^{2}+(L . \theta)^{2}
$$

where $\theta$ is the beam divergence. Under the assumption that the emittance contours are elliptical in phase space, the emittance is given by the product of the waist diameter and the divergence:

$$
\varepsilon=\pi \cdot r_{2} \cdot \theta
$$

$L$ is known, and $r_{1}$ and $r_{2}$ are measured, so that $\theta$, and therefore the emittance, can be determined.

Measurements of BPM traces with the source running at full output $(150 \mu \mathrm{A}$ of $55 \mathrm{keV} \mathrm{C}-$ for $8 \mathrm{kV}$ sputtering voltage) gave $r_{2}=2.7 \mathrm{~mm}, \theta=15 \mathrm{mrad}$, i.e. $\varepsilon=40 \mathrm{~mm}$ mrad at $55 \mathrm{keV}$. In normal operation, the beam waist is shifted slightly downstream from the second BPM to the bouncer gap itself. We estimate that under those conditions $r=3 \mathrm{~mm}, \theta=13 \mathrm{mrad}$. Note that this emittance represents the edges of the beam rather than an RMS value, and probably includes $95-98 \%$ of the total intensity. Also, the quoted value incorporates any emittance increases due to negative-ion space charge effects in the source and extraction region. Although we have measured an overall emittance envelope for all of the beams emerging from the source rather than that of a single massanalyzed beam, recent measurements by von Reden et al. (2005) show that these are similar. Thus, the quoted values are probably good minimum estimates for the acceptance required for an AMS beam transport system to be used with a high-intensity MC-SNICS, though in practice the acceptance should be substantially larger to provide an adequate safety margin.

Since emittance scales as $1 / E^{0.5}$, the measured emittance can be transformed back closer to the source itself. Inside the extractor electrode just downstream of the source, $E=20 \mathrm{keV}$, i.e. $\varepsilon=70 \pi$ $\mathrm{mm}$ mrad. Figure 3 shows an ion source simulation using the PBGUNS Poisson code (Boers 2001). Based on beam marks on a collimator within the extractor, the $90 \mathrm{mrad}$ divergence of the $\mathrm{C}^{-}$beam in the simulation is probably close to the actual value. Thus, looking back from the extractor, the beam emerging from the source appears to be coming from a beam waist with $r=0.8 \mathrm{~mm}, \theta=90$ mrad.

These values will vary with cathode and extractor voltages, and with changes in the extractor geometry. Note that we have used the cylindrical extractor geometry of the modified source in the simulation, not NEC's original small-diameter conical extractor "snout" (e.g. see Figure 5 in 


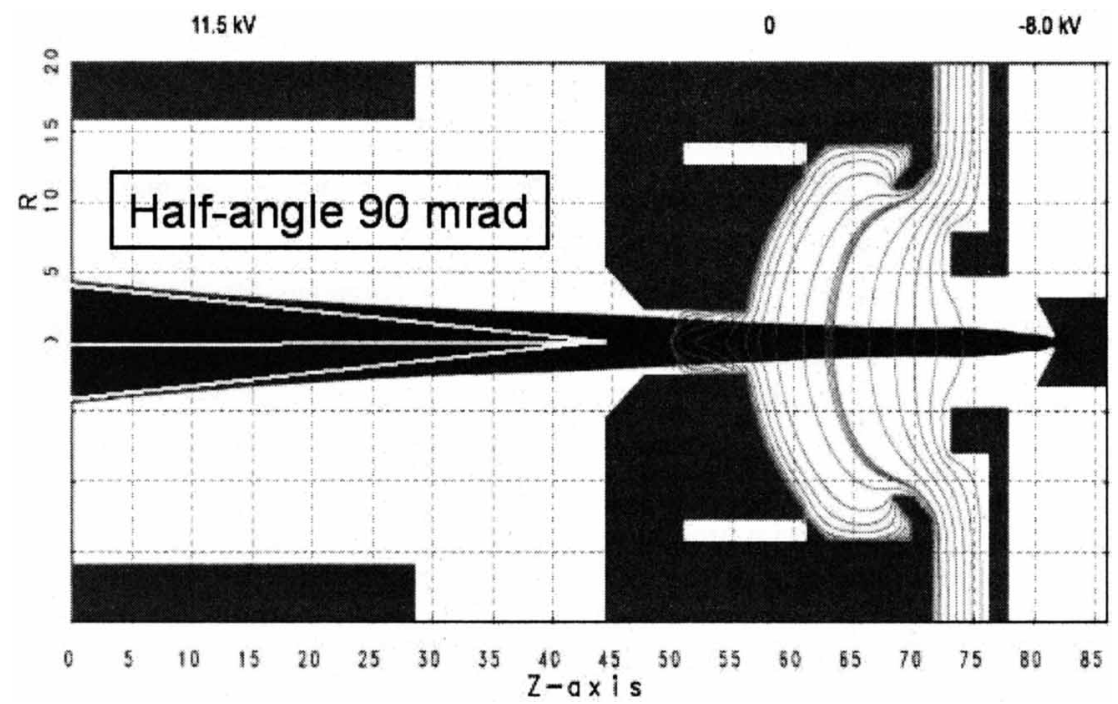

Figure 3 PBGUNS simulation of the negative ion beam from the modified source, with the cathode and immersion lens at the right and the cylindrical extractor electrode at the left. The Cs beam has been omitted from the figure for clarity, but the calculation takes into account space charge effects of both positive and negative ions. Image courtesy of Mark Roberts, Woods Hole Oceanographic Institution.

Southon and Santos [2004]). In addition, the emittance numbers should be treated with some caution because we have neglected space charge effects in the transformation from the measured beam at the downstream waist back to the source. However, they represent first estimates for further calculations to investigate the effects of possible changes to electrode geometries and voltages in the extractor, Einzel lens, and pre-acceleration sections. These results therefore provide the necessary data for investigating how the high-intensity MC-SNICS could be efficiently coupled to the acceptance of other AMS spectrometers.

\section{ACKNOWLEDGMENTS}

This work was supported by the Dean of Physical Sciences, UC Irvine, and by NSF (EAR/IF 0326205). We thank Mark Roberts (WHOI) for the image of the 134-sample source, and the staff of the UCI Physical Sciences machine shop.

\section{REFERENCES}

Boers JE. 2001. Code PBGUNS 5.04, Thunderbird Simulations. 626 Bradfield Drive, Garland, Texas 750426005 , USA.

Norton GA. 1992. Multi-cathode SNICS ion source. In: Benson J, Rowton L, Tesmer J, Darling R, editors. Proceedings of the 25th Symposium of North Eastern Accelerator Personnel (SNEAP). Santa Fe, New Mexico, USA, 16-19 October 1991. Singapore: World Scientific. p 295-8.

Southon JR, Roberts ML. 2000. Ten years of sourcery at CAMS/LLNL - evolution of a Cs ion source. Nuclear Instruments and Methods in Physics Research B 172(1-4):257-61.
Southon JR, Santos GM, 2004. Ion source development at the KCCAMS facility, University of California, Irvine. Radiocarbon 46(1):33-9.

Southon JR, Santos GM. 2007. Life with MC-SNICS. Part II: further ion source development at the Keck Carbon Cycle AMS facility. Nuclear Instruments and Methods in Physics Research B 259(1):88-93.

Southon JR, Santos GM, Druffel-Rodriguez K, Druffel E, Trumbore S, Xu X, Griffin S, Ali S, Mazon M. 2004. The Keck Carbon Cycle AMS Laboratory, University of California, Irvine: initial operation and a background surprise. Radiocarbon 46(1):41-9.

von Reden KF, McNichol AP, Pearson A, Schneider RJ. 
1998. ${ }^{14} \mathrm{C}$ AMS measurements of $<100 \mu \mathrm{g}$ samples with a high-current system. Radiocarbon 40(1):24754.

von Reden KF, Griffin VS, Roberts ML. 2005. Beam profile measurements and modeling calculations for a MC-SNICS source with spherical ionizer [abstract]. 10th International Conference on Accelerator Mass
Spectrometry (AMS10) Conference, Berkeley, California, USA, 5-10 September 2005.

Weisser DC, Lobanov NR, Hausladen PA, Fifield LK, Wallace HJ, Tims SG, Apushkinsky EG. 2002. Novel matching lens and spherical ionizer for a cesium sputter ion source. Journal of Physics (Indian Academy of Sciences) 59(6):997-1006. 